\title{
How Africa learned to love the cow
}

\section{The development of lactose tolerance in sub-Saharan Africa is a fascinating tale of genetic convergence, reports Erika Check.}

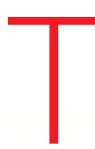

he Dinka people of southern Sudan, it is said, have 400 different words to refer to the cattle that they prize above all other things. The Maasai, who live in Kenya and northern Tanzania, have traditionally believed that all cattle on Earth were given to them by the gods, and value those in their possession accordingly. The Zulu, Xhosa and Swazi in South Africa devote themselves to their strikingly patterned Nguni cattle, whose hides are now prized by high-end interior designers.

And in all these pastoralist or semi-pastoralist groups, which rely on herding for survival, people drink milk - which is something of a puzzle. Most adult humans (those of European stock are largely an exception) find the sugar in milk, called lactose, indigestible. The gene for lactase, the enzyme that breaks lactose down into the more digestible forms of glucose and galactose, is normally switched off as children are weaned. Without lactase, lactose is of little use to a milk drinker; but it is still a valid food for some stomach bacteria, which can have unsettling and unpleasant results. Thus, most adults tend not to drink much milk.
Now, genetic detective work is showing how, in parts of Africa, evolution found a way round this problem - just as it did a few thousand years earlier in northern Europe. The results should help clarify the origins and spread of cattle rearing in Africa, and provide a textbook illustration of the ways in which the same social innovation can write its consequences into the human genome in different times and places.

\section{A drinking game}

Sarah Tishkoff of the University of Maryland, College Park, first heard the story of 'lactase persistence' - the ability to continue making lactase throughout adult life - in an introductory anthropology course she took at college in the late 1980s. In the 1960s, anthropologists first started noticing that groups of humans that raise cattle also tended to be the same ones that could drink milk as adults ${ }^{1}$. In the 1970s, a genetic basis for lactose intolerance was established, although the nature of the mutation has remained a mystery ${ }^{2}$. Drinking milk thus came to be seen as a metabolic, not merely cultural, proclivity. People whose ancestors had herded cattle had evolved to make use of their milk.
In places where lactase persistence is rare, the milk that is drunk is frequently sour - its lactose content lowered by hungry bacteria.

But it was not until 1997, when Tishkoff was doing postdoctoral research with Andy Clark at Pennsylvania State University, that she began thinking about lactase persistence as a focus for her own work. Tishkoff visited geneticist Trevor Jenkins at the University of Witwatersrand in Johannesburg, South Africa, to help him study an extensive collection of DNA samples from southern Africans. She began to wonder whether she could trace the genetic origin and history of lactase persistence by studying the DNA of Africa's cattle herders. If so, it would be a neat piece of genetics. And it would also be of interest to anthropologists interested in cattle domestication itself. Had the ancestral aurochs been domesticated just once, in the middle East, and the practice then spread to Europe and Africa? Or had Africans learned to domesticate cattle on their own?

Tishkoff designed a project to collect DNA samples from 43 ethnic groups in three East African countries and to correlate the data with various physiological characteristics relevant
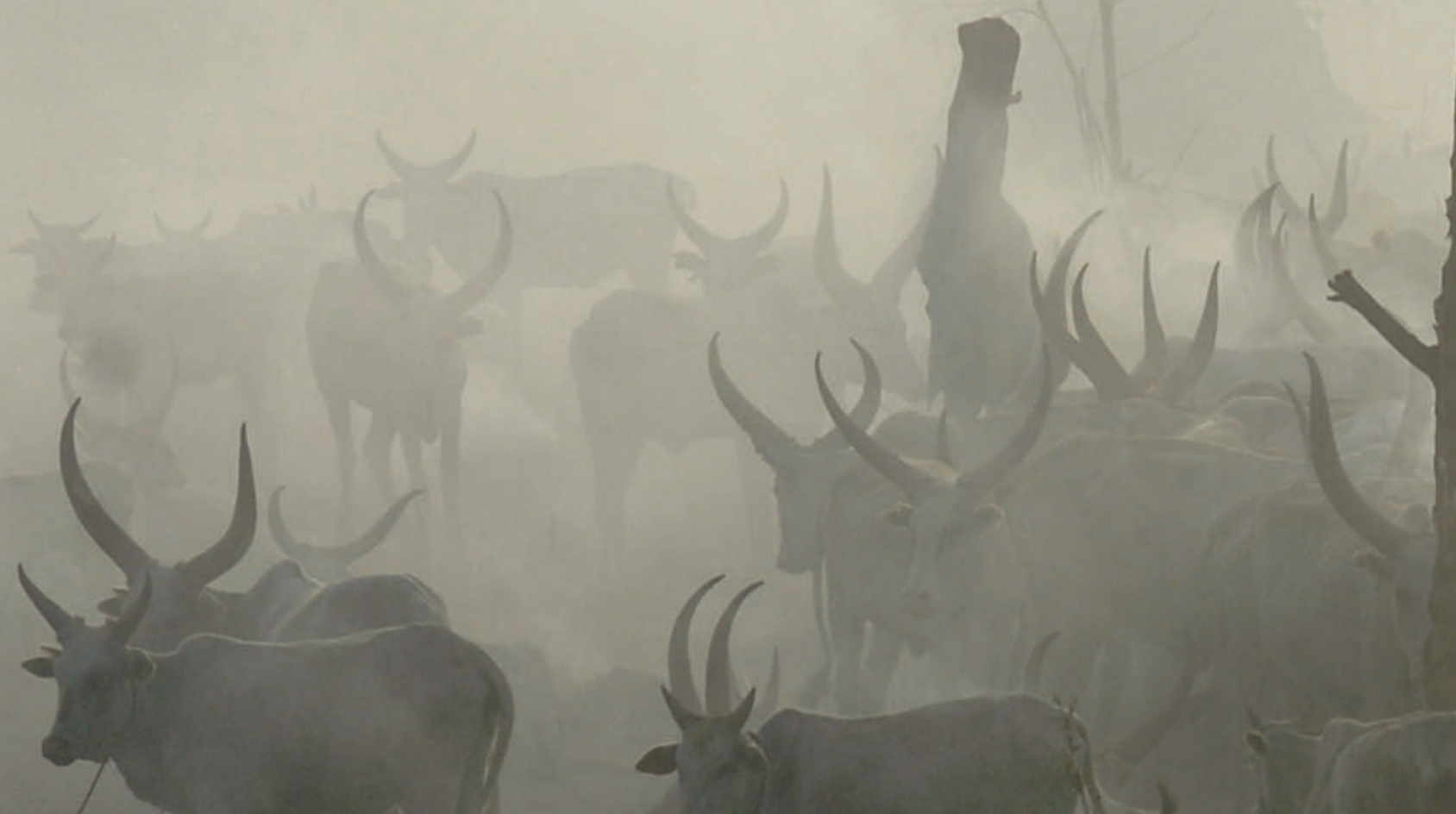
to taste perception, disease susceptibility and other things - including lactose metabolism. It was an ambitious plan at best - a foolhardy undertaking at worst. Few researchers, if any, had ever collected such a large, diverse set of genetic samples from Africa. Many of the groups she wanted to study were in remote locations, isolated by choice or by circumstance. And although she started to apply for permission to research in Tanzania in 1999, she didn't get permission to work there until 2001.

\section{Living on the edge}

Tishkoff set out with a 30-year-old Land Rover full of cases of energy bars and camping gear. Over the next three years, on and off, she and her students roamed around Tanzania, Kenya and Sudan, collecting data in some dangerous as well as out of the way places - such as parts of Kenya where carjacking was rampant and everyone carried semi-automatic weapons. The team also had a close call once, on a journey near Lake Eyasi in Tanzania, when a bus rounded a corner and smashed head-on into the Land Rover; miraculously, no one was hurt. Tishkoff credits her students - especially Jibril Hirbo and Alessia Ranciaro, who collected samples in the most dangerous parts of Kenya - with persistence and courage. "Those guys literally risked their lives for this work," Tishkoff says.

At most stops, Tishkoff's group hired a translator to explain the purpose of her research, get permission from local leaders, and recruit

people for their research. In all, they took samples from 470 people. To test for lactase, the team members stirred powdered lactose into cups of water, gave it to each person, and took a series of timed blood samples. That told the researchers how well each person could digest lactose, as well as providing samples of the individual's DNA.

In 2002, while the work was under way, a team of Finnish researchers reported that it had found a genetic mutation that seemed to cause lactase persistence in North Europeans ${ }^{3}$. A small change in an 'enhancer' region upstream of the lactase gene seemed to keep the gene from being switched off after infancy. All of the 137 lactase-persistent Finns studied had the mutation in question, and studies of other populations showed that

"Until the geneticists contributed to the data, we thought about evolution as happening very slowly and gradually." - Diane GiffordGonzalez postdoctoral fellow working with her, Floyd Reed, noticed that one of these mutations was tightly linked to lactase persistence in Tanzanians and Kenyans. The team also found that two other mutations were associated with lactase persistence in people in northern Kenya and Sudan, though not as strongly ${ }^{5}$. It was immediately clear that these mutations had arisen independently from the one found in Finland. the frequency of the mutation matched that of the lactase persistence. But two years later, another team reported that the Finns' genetic variant was not found in East Africans, even though some are lactase persistent ${ }^{4}$.

Tishkoff's team showed why this was. Ranciaro sequenced DNA from her subjects and noticed several mutations close to the lactase gene. A collaborator at the Wellcome Trust Sanger Institute in Cambridge, UK, Panos Deloukas, checked for the mutations in the full set of 470 people, and Tishkoff and a

\section{Quick start}

The DNA also showed evidence that the mutation seen in the Tanzanians had spread very quickly. DNA accumulates small, random imperfections over the generations, and yet the stretches of DNA surrounding the lactase persistence mutation were identical in most of those who had it. This uniformity shows that the gene evolved recently and spread rapidly — which in turn means that it must have conferred an advantage strongly selected for by evolution. Statistical models of Tishkoff's data suggest that the mutation arose between 3,000 and 7,000 years ago - a blink of an eye in evolutionary time.

Tishkoff and Reed conclude that lactase persistence bears one of the strongest signatures of positive selection ever observed in the human genome. Mutations that favour

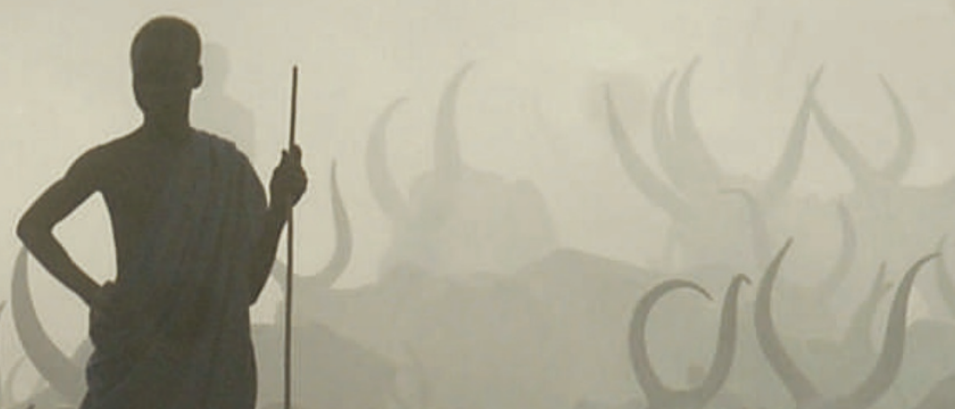


malaria resistance, such as the sickle-cell gene and an inability to make the enzyme glucose6-phosphate dehydrogenase, or G6PD, are also strongly favoured and spread rapidly. (They seem to have got going at about the same time, too, and are also related to domestication malaria is thought to have first become a major problem for Africans when they started to live in settlements.) But the positive selection for lactase persistence seems even stronger, perhaps because the costs of the mutation are less severe than those for malaria. Tishkoff and Reed suspect that the advantage might go beyond the extra calories that could be gained from the lactose. Lactase persistence might also have allowed people to stay alive during times of drought, when those benefiting from the mutation would have been able to drink milk without the risk of diarrhoea, which exacerbates dehydration.

The study, and subsequent follow-up, should help to elucidate the origins of East African
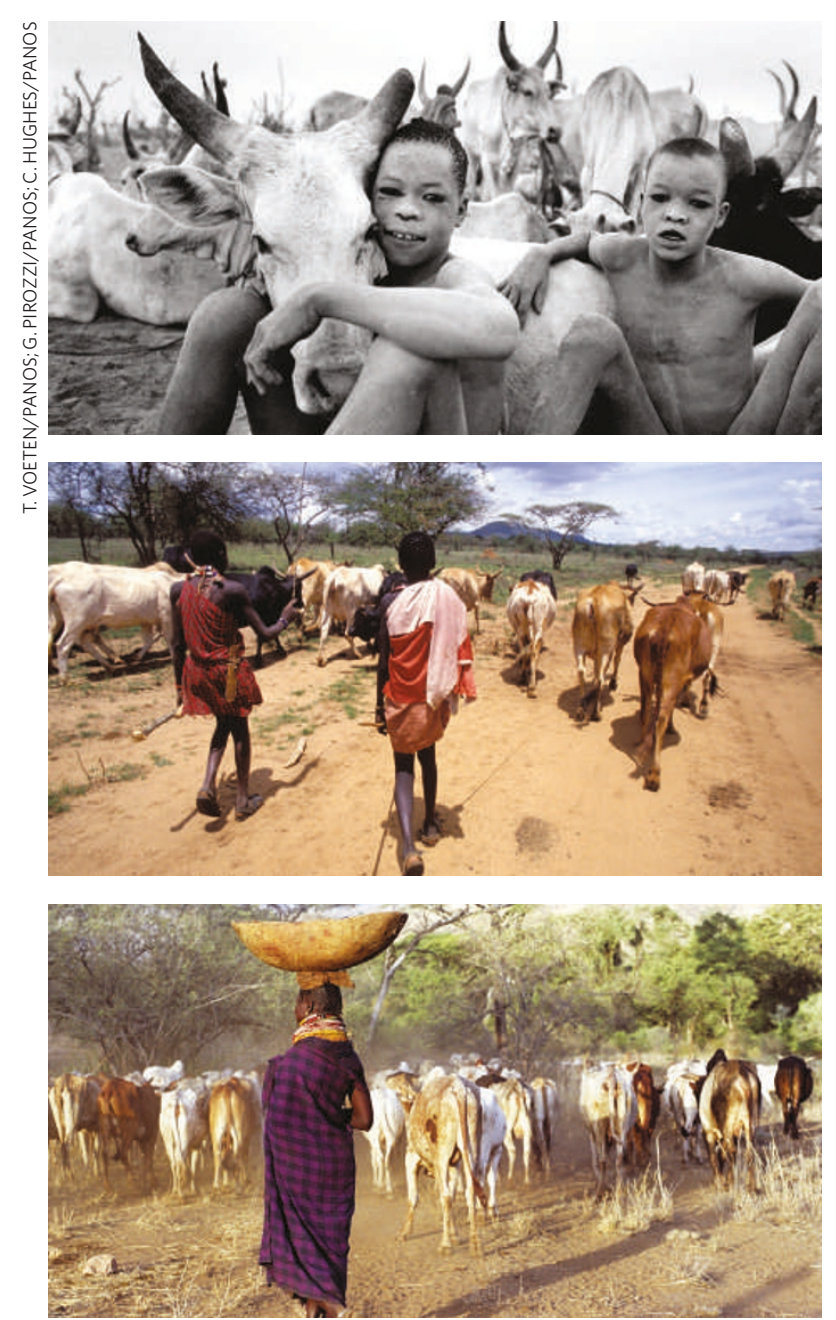

Cattle call: the ability to drink milk is a useful trait with a variety of origins. cultures and traditions. Anthropologists such as Diane Gifford-Gonzalez from the University of California, Santa Cruz, one of the world's experts on the origins of herding, say that these genetic data are changing the way they think about human history. "Until the geneticists contributed to the data, the rest of us always thought about evolution happening very slowly and gradually."

\section{Herding along evolution}

And the genes provide data even in places, such as East Africa, where the archaeological data are poor. "That is why this article is so interesting to people like me," says Gifford-Gonzalez. "This gives us a totally independent line of evidence about the origins of dairying, and gives us a much better way of homing in on when these major nutritional transitions occurred." The human genetic data might thus in some ways complement the genetic data on cattle, which in the decade since Tishkoff began thinking about the issue have come down in favour of multiple domestications, including one in Africa.

Tishkoff's work also highlights the incredible genetic diversity in African people, a diversity that as yet has been studied very little. For example, the African DNA samples in the Haplotype Map ${ }^{6}$ the catalogue of genetic diversity published last year - come from only one ethnic group: the Yoruba of West Africa. But, traditionally, the Yoruba don't herd cattle, and Tishkoff didn't discover any mutations for lactase persistence in them (although in some populations of West African pastoralists, fewer people have the 'European' lactase persistence mutation). Such blindspots could be a problem, because scientists hunting for the genetic causes of diseases often rely on HapMap data. "There's such a huge amount of genetic diversity in Africa that we're clearly going to have to look at all the ethnic groups in different regions to find all the variants,"

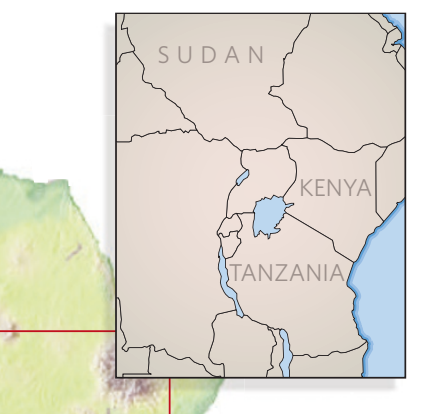

Tishkoff says. "Otherwise, we could be completely missing things that are important in disease." She worries that the fragmentation and disappearance of traditional cultures will make it harder to access and understand that diversity in the future.

The lactose work still leaves a lot of questions unanswered, and the possibil-

ity of more adaptations still to be found. A particularly intriguing question surrounds the Hadza of Tanzania, who show a surprisingly high level of lactase persistence despite having very little to do with cattle. One possibility is that, though they are now mainly hunter-gatherers, their ancestors might have been pastoralists. Another is that lactase may offer some other benefits besides the ability to drink milk — perhaps aiding in the digestion of some specific local foods.

\section{A textbook case}

But if there are still questions, there's also a significant achievement. Scientists have to date found little genetic evidence for convergent evolution in people: "This is the best example of convergent evolution in humans that I've ever seen," says Joel Hirschhorn, a geneticist and paediatrician at Children's Hospital Boston, Massachusetts. "Lactase persistence has always been a textbook example of selection, and now it'll be a textbook example in a totally different way."

Convergent evolution is not unknown in humans; lighter skin colour seems to have evolved independently in Europe and Asia, and a range of different malaria adaptations are known. But lactase persistence offers a particularly simple and tractable example: there's a single gene involved, with different mutations in different parts of the world having similar effects. The challenge now is to learn from this textbook example how to spot more subtle convergences that have been forced on human biology by shared experiences and cultural innovations - or that are still under way today.

Erika Check is a senior reporter for Nature in San Francisco.

1. Swallow, D. M. Annu. Rev. Genet. 37, 197-219 (2003).

2. Sahi, T. Scand. J. Gastroenterol. Suppl. 1-73 (1974).

3. Enattah, N. S. et al. Nature Genet. 30, 233-237 (2002)

4. Mulcare, C. A. et al. Am. J. Hum. Genet. 74, 1102-1110 (2004).

5. Tishkoff, S. A. et al. Nature Genet. doi:10.1038/ng1946 (2006).

6. The International HapMap Consortium Nature 437, 1299-1320 (2005). 